\title{
A visual analysis of the research on the use of mobile phones by college students based on VOSviewer
}

\author{
Han Xiyang* \\ Affiliated Hospital, Hunan University of Science and Technology, Xiangtan, 41120, China \\ E-mail: hanxiyang1975@sina.com
}

Received:21 June 2020; Accepted: 15 July 2020; Published: 08 December 2020

\begin{abstract}
The problem of cell phone addiction has severely affected college students' physical and mental health. Using VOSviewer, this paper analyzed 101 articles on college students and mobile phones in the CNKI database (China National Knowledge Infrastructure) from 2003 to 2019. The results showed that: in 2014, the relevant research on college students and mobile phones was relatively hot, with a total of 19 articles published and a total of 429 times cited, and then the number of papers began to reduce. The top 10 institutions with the largest number of documents are all universities. In the distribution of journals and disciplinary fields, higher education and vocational education are the main directions. The analysis of keyword co-occurrence, mobile phone addiction, research on ideological and political education, and new media are still relatively popular. The four categories of mobile phone addiction, ideological and political education, new media, and mobile phone culture, are the core of the current research on mobile phone use by college students through the keyword cluster analysis. The results can not only provide a reference for the research direction and hot spot selection of college students and mobile phone related issues, but also help to explore the influencing factors and prevention of mobile phone use on college students' psychological and physical health.
\end{abstract}

Index Terms: VOSviewer; college students; mobile phone addiction; visualization

\section{Introduction}

As a new medium, mobile phones can break through the limitation of time and space. It has the traditional functions of newspapers, magazines, radio, and television, as well as the enormous extension of vision, hearing, and touch. With the continuous enrichment of mobile internet service scenarios and the mobile terminal scale's acceleration, the mobile data volume is keeping expanding [1]. The characteristics of mobile phones, such as instantaneity, decentralization, mobility, interactivity, and privatization, effectively integrate the modes and functions of mass communication and interpersonal communication, turning mobile phones from "communication tools" to "personal multimedia terminals", resulting in unprecedented dependence on mobile media [2].

According to "The 45th China Statistical Report on Internet Development", "By March 2020, the number of Internet users in China was 904 million, an increase of 75.08 million compared with the end of 2018, and the Internet popularization rate reached 64.5\%, an increase of 4.9 percentage points compared with the end of 2018. " [3] Among them, internet users aged 0-29 accounted for 21.5\%, higher than other age groups. Among the Internet users in China, students are the most, accounting for $26.9 \%$. The number of mobile instant messaging users reached 890 million, an increase of 110 million over the end of 2018, accounting for $99.2 \%$ of mobile internet users. The International Telecommunication Union (ITU) refers to the young people born in the digital era and growing up with information and communication technology every day as "Digital Natives", which is defined as "Networked Youth aged 15-24 with five years or more internet experience" (ITU, 2013) [4]. With the rapid development of the internet and modern communication technology, mobile phones have become an indispensable part of college students' study and life because of its convenience and universality. However, there are also many problems in applying mobile phones as a media culture carrier [5]. The use of mobile phones by college students has become more and more frequent. The excessive use of mobile phones has caused some college students to rely heavily on them, severely affecting their studies and society [6]. The survey results show that only $14.05 \%$ of the respondents use mobile phones for 3 hours or less every day, and $24.75 \%$ of students use mobile phones for more than 8 hours. The phenomenon of "mobile phone addiction" has aroused widespread concern and has become a hot topic in the theoretical field [2,7].

As a new research method, knowledge mapping has been widely used in various disciplines in recent years. Knowledge mapping is based on the principles of mathematics and statistics. It uses mathematics, graphics, information 
science, information visualization technology, and other theories to conduct a quantitative analysis of the literature in a specific research field. Through certain data processing and graphics drawing, research hotspots, development trends, and future research directions can be visually displayed $[8,9,10]$. Many applications such as Bibexcel, BICOMB, SATI, CiteSpace, VOSviewer, UCINET, and NetDraw have sprung up [11]. VOSviewer, designed and developed by CWTS of Leiden University in the Netherlands, is widely used because of its easy use and beautiful graphics in co-occurrence analysis of keywords, topic words, and authors. Besides, VOSviewer has unique advantages in clustering technology [9, 12, 13, 14]. However, there is no relevant bibliometric research on mobile phone use among college students based on VOSviewer.

In this paper, the VOSviewer is used to measure and analyze the research literature related to college students and mobile phones in the CNKI database in the past ten years and show the research hotspot and trend in charts and knowledge maps.

\section{Data sources and methods}

The primary data of this paper is the journal articles collected by CNKI from 2003 to 2019. The search conditions are as follows:

Database scope: SCI, EI, CSSCI, CSCD

Search the topic "college students" and match the keyword "mobile phone".

The search type is an academic journal.

A total of 101 core periodicals articles were retrieved. This paper attempts to use the VOSviewer software to draw the research literature's visual scientific knowledge map related to college students and mobile phones, and summarize the research status.

VOSviewer is free Java-based software developed by Van Eck and Waltman of the Centre for Science and Technology Studies (CWTS) in 2009. It is mainly oriented to literature data and focuses on the visualization of scientific knowledge [15]. However, VOSviewer can not directly process CNKI data, so data conversion is needed. Firstly, the specific transformation method is to export the searched literature to data in endnote format, then use Endnote software to transform and organize the exported literature, and finally use VOSviewer to analyze and visualize them, and get the knowledge map [16].

\section{Results}

\section{1 literature age and cited quantity analysis}

In the past decade, among the research on mobile phone problems related to college students, 19 articles were published in 2014. Before 2010, the number of issued articles had been low and developed steadily. Since 2010, the number of published articles has gradually increased and continued until 2017, peaking in 2014. After 2017, it declined sharply. In 2004, 2007, and 2019, there was only one publication (Fig. 1).

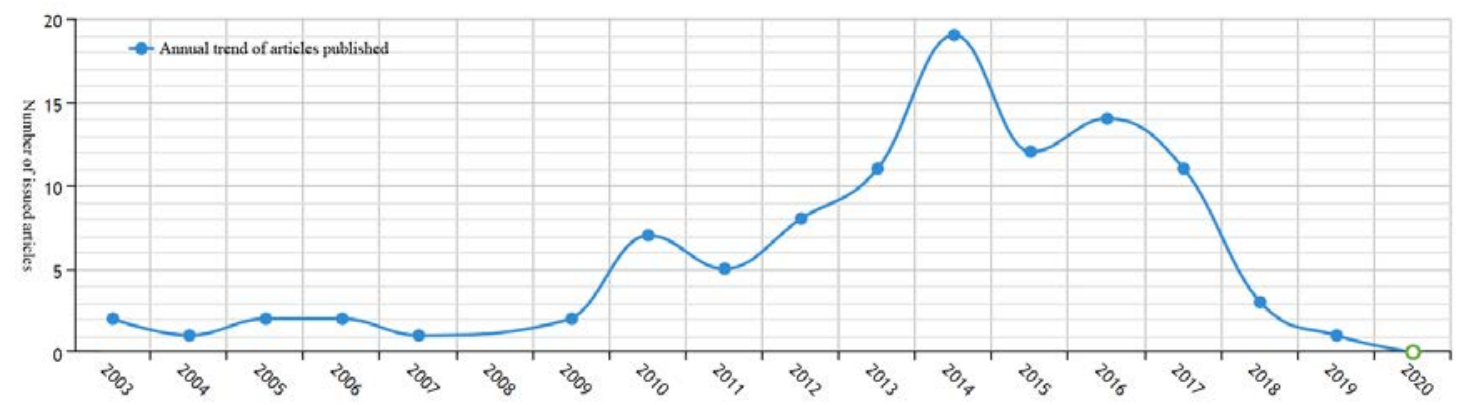

Fig.1. The number of issued articles on mobile phone use of college students in 2003-2019

\subsection{Literature organization distribution}

The distribution of research institutions can reflect the research strength and position of different research institutions in this field [2]. From 2003 to 2019, Inner Mongolia Normal University and Inner Mongolia University for Nationalities issued the most papers, with 12 papers, accounting for $11.88 \%$ of the total. Nanjing University published three papers, accounting for $2.97 \%$ of the total. The second was Inner Mongolia University of Finance and Economics, Fudan University, Zhejiang University, Central South University, Nanjing University of Posts and Telecommunications, Gannan Normal University, and Zhejiang Yuexiu University of Foreign Languages, accounting for $13.86 \%$ of the total (Table 1). Overall, the difference between the first ten institutions is relatively significant, and there are four articles differences 
between the first, second, and tenth.

Table 1. Top 10 research institutions of the study on the use of mobile phones by college students in 2003-2019

\begin{tabular}{|c|c|c|c|}
\hline Ranking & Organization name & Number of issued articles & $\begin{array}{l}\text { Proportion in the total } \\
\text { number of issued } \\
\text { articles (\%) }\end{array}$ \\
\hline 1 & Inner Mongolia Normal University & 6 & 5.94 \\
\hline 2 & Inner Mongolia University for Nationalities & 6 & 5.94 \\
\hline 3 & Nanjing University & 3 & 2.97 \\
\hline 4 & $\begin{array}{l}\text { Inner Mongolia University of Finance and } \\
\text { Economics }\end{array}$ & 2 & 1.98 \\
\hline 5 & Fudan University & 2 & 1.98 \\
\hline 6 & Zhejiang University & 2 & 1.98 \\
\hline 7 & Central South University & 2 & 1.98 \\
\hline 8 & $\begin{array}{l}\text { Nanjing University of Posts and } \\
\text { Telecommunications }\end{array}$ & 2 & 1.98 \\
\hline 9 & Gannan Normal University & 2 & 1.98 \\
\hline 10 & $\begin{array}{l}\text { Zhejiang Yuexiu University of Foreign } \\
\text { Languages }\end{array}$ & 2 & 1.98 \\
\hline Total & & 29 & 28.71 \\
\hline
\end{tabular}

\subsection{Fund distribution of literature}

If the published literature has the corresponding fund support, it shows that this research direction has a particular value while reflecting specific research trends and directions [17]. From 2003 to 2019, fund projects with the largest number of papers was the National Social Science Fund of China, with six articles, accounting for 5.94\% of the total, followed by the National Natural Science Foundation of China (Table 2). The local fund support perspective mainly focuses on Jiangsu, Hunan, and Zhejiang, which shows that these three provinces pay more attention to this research area.

Table 2. Top 7 fund projects related to research on mobile phone use of college students in 2003-2019

\begin{tabular}{llll}
\hline Ranking & Fund name & $\begin{array}{l}\text { Number of issued } \\
\text { articles }\end{array}$ & $\begin{array}{l}\text { Proportion in the total number of } \\
\text { issued articles (\%) }\end{array}$ \\
\hline & & 6 & 5.94 \\
2 & National Social Science Fund of China & 4 & 3.96 \\
3 & National Natural Science Foundation of China & 2 & 0.99 \\
4 & Research Fund for Humanities and social sciences of Jiangsu & 2 & 0.99 \\
5 & Provincial Department of Education & 1 & 0.99 \\
6 & Research Fund of Hunan Provincial Education Commission & 1 & 0.99 \\
7 & Scientific research plan of Education Department of Zhejiang & 1 & 15.84 \\
\hline
\end{tabular}

\subsection{Journal source distribution of literature}

"Education and Vocation" has the largest number of articles, 14 in total, accounting for 13.86\%. Its main research fields are higher education and vocational education. Next are "China Youth Study" and "Chinese Journal of School Health", with four papers, 3.96\%. The main subject areas of "China Youth Study" are sociology and statistics, political parties, and mass organizations, while the main subject areas of the "Chinese Journal of School Health" are preventive medicine and hygiene, educational theory, and educational management (Table 3). However, the top 10 journals have various research fields, but most are higher education, news and media, and other education fields related to college students' age. 
Table 3. Distribution of top 10 research periodicals on mobile phone use of college students in 2003-2019

\begin{tabular}{|c|c|c|c|c|}
\hline Ranking & Journal sources & Main disciplinary field & $\begin{array}{l}\text { Number of } \\
\text { issued } \\
\text { articles }\end{array}$ & $\begin{array}{l}\text { Proportion in the total } \\
\text { number of issued } \\
\text { articles (\%) }\end{array}$ \\
\hline 1 & Education and Vocation & higher education, vocational education & 14 & 13.86 \\
\hline 2 & China Youth Study & $\begin{array}{l}\text { sociology and statistics, political parties and } \\
\text { mass organizations }\end{array}$ & 4 & 3.96 \\
\hline 3 & $\begin{array}{l}\text { Chinese Journal of } \\
\text { School Health }\end{array}$ & $\begin{array}{l}\text { preventive medicine and hygiene, educational } \\
\text { theory and educational management }\end{array}$ & 4 & 3.96 \\
\hline 4 & Market Modernization & enterprise economy, trade economy & 3 & 2.97 \\
\hline 5 & Youth Journalist & news and media, publishing & 3 & 2.97 \\
\hline 6 & $\begin{array}{l}\text { Shanghai Journalism } \\
\text { Review }\end{array}$ & news and media, publishing & 2 & 1.98 \\
\hline 7 & $\begin{array}{l}\text { Library and Information } \\
\text { Service }\end{array}$ & $\begin{array}{l}\text { library information and digital library, } \\
\text { computer software and computer application }\end{array}$ & 2 & 1.98 \\
\hline 8 & The Press & news and media, higher education & 2 & 1.98 \\
\hline 9 & $\begin{array}{l}\text { The Party Building and } \\
\text { Ideological Education in } \\
\text { Schools }\end{array}$ & higher education, Communist Party of China & 2 & 1.98 \\
\hline 10 & China Adult Education & $\begin{array}{l}\text { Higher education, adult education, special } \\
\text { education }\end{array}$ & 2 & 1.98 \\
\hline Total & & & 38 & 37.62 \\
\hline
\end{tabular}

\subsection{Distribution of disciplinary field of literature research}

From the survey results, it can be seen that the main disciplinary area is higher education, news and media, and other education fields. Most provinces support such research by their education departments (Table 4). Because this paper selects the related research literature of college students' use of mobile phones, it has the closest connection with the education department and more support.

\subsection{Co-author analysis}

According to the co-author's analysis, only 4 of 193 authors have published two or more articles. Jiang Yongzhi, from the School of Education Science of Inner Mongolia Normal University, has published the most articles, six articles in total. Next is Bai Xiaoli, with five articles in total; then are Wang Haixia and Alatan Bagen, with two articles (Table 4). The strength of partnership among the top ten authors is still strong. The calculation results of the VOSviewer showed that the maximum connection strength was 13.

\subsection{Keywords co-occurrence analysis}

Through the keywords co-occurrence analysis of VOSviewer, 261 keywords were obtained, and only six keywords appeared five times or more (Table 5). Except for the two search qualifiers, "mobile phone" and "college students", it can be seen that "mobile phone dependence", "ideological and political education", "new media", and "mobile phone culture" are frequent. Among them, "mobile phone dependence" appeared 11 times, which may be a common problem for college students, so it has been widely considered. There are seven times of "ideological and political education". The reason for its high frequency is that the mobile phone has become a "personal mobile multimedia" terminal for college students to obtain information. The bad habit of using a mobile phone has brought many problems to college students' lives and studies, so corresponding ideological and political education must be carried out. The frequency of "new media" and "mobile phone culture" is also relatively high, which is related to the continuous development of mobile phone culture, and has been regarded as a new culture that changes and affects human daily life and ideology [18].

For each of the six keywords, calculate the total strength of their co-occurrence links with other keywords, and get a label view of the keyword co-occurrence analysis. This chart reflects the close relationship between these keywords. The results showed that these keywords are grouped into six categories (Table 6, Fig. 2). At the same time, it can be seen from the keyword co-occurrence density view (Fig. 3), "mobile phone", "college students", "mobile phone dependence", "ideological and political education", and "mobile phone culture" are the hot areas of concern. 
Table 4. Co-author situation

\begin{tabular}{|c|c|c|c|c|}
\hline Ranking & Author & Author's Work unit & $\begin{array}{l}\text { Number } \\
\text { of issued } \\
\text { articles }\end{array}$ & $\begin{array}{l}\text { Proportion in the total } \\
\text { number of published } \\
\text { articles (\%) }\end{array}$ \\
\hline 1 & Jiang Yongzhi & $\begin{array}{l}\text { School of Education Science, Inner Mongolia } \\
\text { Normal University }\end{array}$ & 6 & 5.94 \\
\hline 2 & Bai Xiaoli & $\begin{array}{l}\text { Institute of Mental Health Education of School } \\
\text { of Education Sciences of Inner Mongolia } \\
\text { Normal University }\end{array}$ & 5 & 4.95 \\
\hline 3 & Wang Haixia & Experiment Middle School of Tongliao & 2 & 1.98 \\
\hline 4 & Alatan Bagen & $\begin{array}{l}\text { Institute of Mental Health Education of School } \\
\text { of Education Sciences of Inner Mongolia } \\
\text { Normal University }\end{array}$ & 2 & 1.98 \\
\hline 5 & Yu Shouhua & $\begin{array}{l}\text { College of Mathematics and Informatics of } \\
\text { South China Agricultural University }\end{array}$ & 1 & 0.99 \\
\hline 6 & Liu Yong & $\begin{array}{l}\text { Mental Health Education and Counseling } \\
\text { Center of Jiamusi University }\end{array}$ & 1 & 0.99 \\
\hline 7 & Wu Jiayong & $\begin{array}{l}\text { College of Mathematics and Informatics of } \\
\text { South China Agricultural University }\end{array}$ & 1 & 0.99 \\
\hline 8 & Wu Yingchun & $\begin{array}{l}\text { College of Mathematics and Informatics of } \\
\text { South China Agricultural University }\end{array}$ & 1 & 0.99 \\
\hline 9 & Zhuang Xiangpeng & $\begin{array}{l}\text { College of Mathematics and Informatics of } \\
\text { South China Agricultural University }\end{array}$ & 1 & 0.99 \\
\hline 10 & Zeng Maojing & $\begin{array}{l}\text { College of Mathematics and Informatics of } \\
\text { South China Agricultural University }\end{array}$ & 1 & 0.99 \\
\hline Total & & & 21 & 20.79 \\
\hline
\end{tabular}

Table 5. Keyword co-occurrence analysis

\begin{tabular}{llll}
\hline Ranking & keywords & Number of occurrences & Total connection intensity \\
\hline 1 & mobile phone & 41 & 137 \\
2 & college student & 34 & 105 \\
3 & $\begin{array}{l}\text { mobile phone } \\
\text { dependence }\end{array}$ & 11 & 35 \\
4 & $\begin{array}{l}\text { ideological and } \\
\text { political education }\end{array}$ & 7 & 22 \\
5 & new media & 5 & 16 \\
6 & mobile phone culture & 5 & 15 \\
Total & 103 & 330 \\
\hline
\end{tabular}

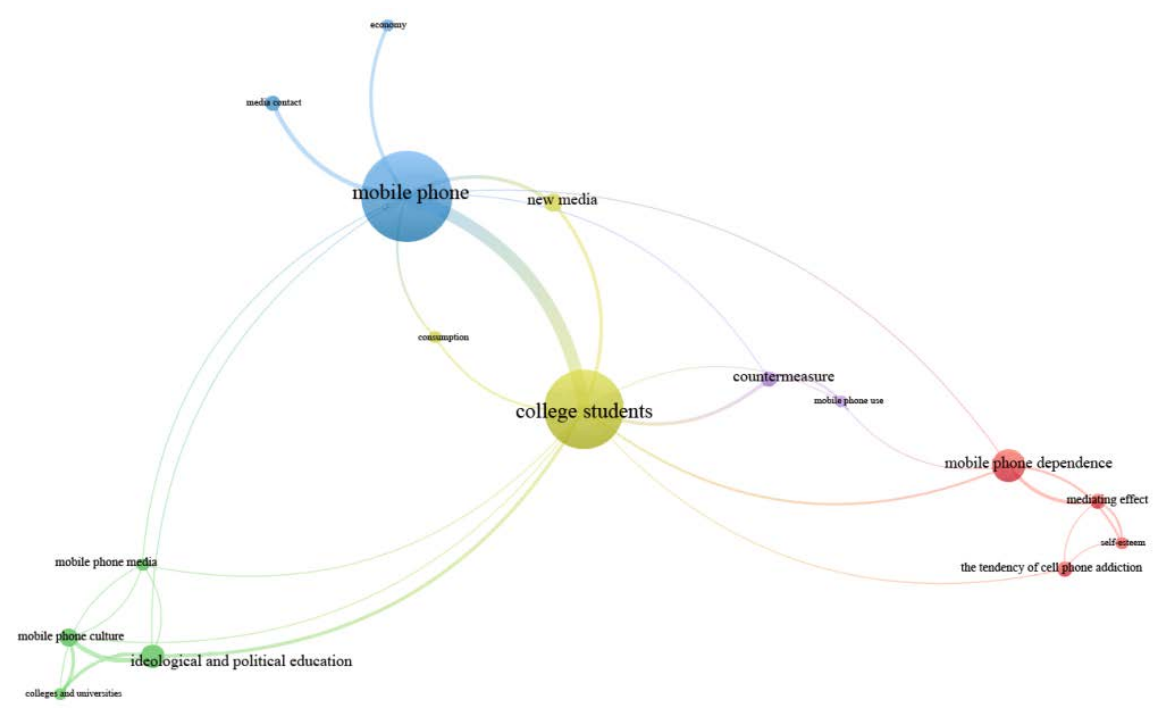

Fig.2. Keywords co-occurrence map 
Table 6. keywords clustering of mobile phone use research of college students

\begin{tabular}{ll}
\hline Category & Keywords \\
\hline Category I & mediating effect \\
& mobile phone dependence \\
& the tendency of cell phone addiction \\
& self-esteem \\
Category II & ideological and political education \\
& mobile phone media \\
& mobile phone culture \\
& colleges and universities \\
Category III & media contact \\
& mobile phone \\
Category IV & economy \\
& college students \\
Category V & new media \\
& consumption \\
& countermeasure \\
\end{tabular}

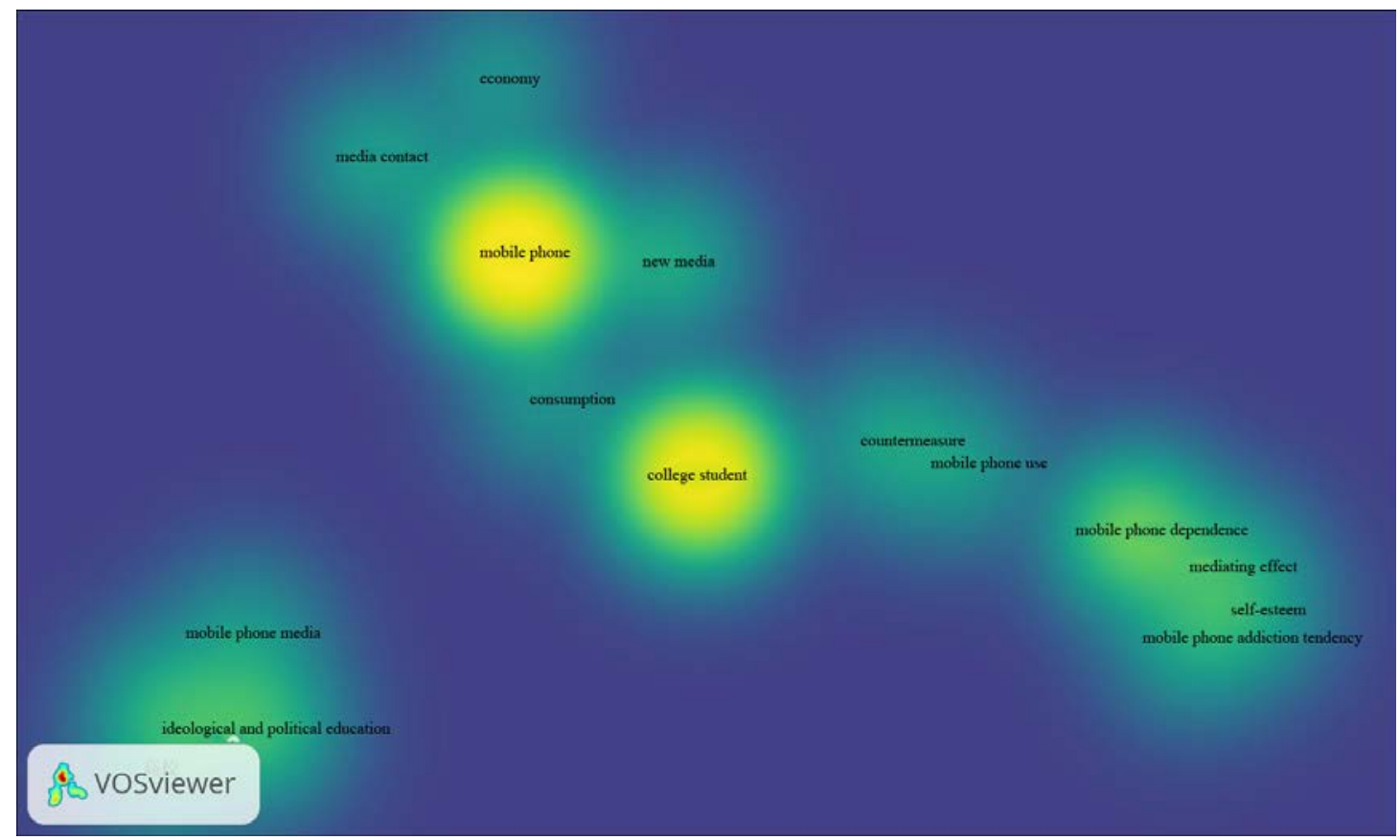

Fig.3. Keywords of the co-occurrence density map

\section{Conclusion}

This paper uses VOSviewer to summarize and analyze the topic of college students' use of mobile phones and shows the research hotspot and trend in this field in the recent ten years in China through the knowledge map. The research on this issue was relatively hot in 2014, with 19 articles published and 429 cited, and the subsequent research began to decrease. The top 10 institutions are all colleges and universities. It can be seen that colleges and universities pay more attention to research on the related problems of college students' use of mobile phones. In the distribution of journals and disciplinary fields, higher education, news and media, and other educational areas are the main directions of this study. In the keywords co-occurrence analysis, it can be seen that for the current college students, "mobile phone dependence", "Ideological and political education", "mobile phone culture" research is still relatively popular. At present, Chinese college students generally rely on mobile phones [19, 20]. There will be panic, impatience, distraction, and other severe effects on learning and life as long as there is no mobile phone around [21]. At the same time, keywords cluster analysis also shows that "mobile phone dependence", "ideological and political education", "mobile phone culture", and 
"countermeasures" are the focus of attention in this field. With the help of VOSviewer, this paper made a detailed analysis. It clarified the current situation, hot spots, and future research direction, which can not only assist in exploring the influencing factors and prevention of mobile phone use on college students' psychological and physical health, but also provide an essential reference for future research.

\section{References}

[1] China Internet Network Information Center. The 41st China Statistical Report on Internet Development. 2018.

[2] Rong Ting. Study on the influence of cell phone dependence intensity on college students' physical and mental health, interpersonal relationship and learning efficiency - an empirical analysis based on investigation of 2240 colleges in China. Heilongjiang Researches on Higher Education, 2018,36(06):114-118.

[3] China Internet Network Information Center. The 45th China Statistical Report on Internet Development. 2020.

[4] Huang Yan, Xu Jianlin. A study on the mobile phone addiction and peer interaction of college students of "Digital Natives" Taking C University in N city as an example. Education Modernization, 2019,6(61):266-267+272.

[5] Shang Qi-yuan. Based on mobile media to explore the construction of college campus culture in the mobile internet era. Journal of Anhui Vocational College of Metallurgy and Technology, 2016,26(04):63-66.

[6] Gui Jie, Shao Xun. The influence mechanism of positive psychology on mobile phone dependence of higher vocational students - Taking a higher vocational college questionnaire as an example. Journal of Ezhou University, 2019,26(06):72-74.

[7] Tian Chenghui, Liu Weihua. Research on the influence of mobile phone dependence on college students' interpersonal skills and sports intervention. Sichuan Sports Science, 2020,39(03):114-117.

[8] Yang Rui, Wang Guangming, Zhang Liansheng. Research on the Hotspots of School Culture in China - Co-occurrence Analysis of Key Words Based on VOSviewer. Journal of Tianjin Normal University (Elementary Education Edition), 2020,21(2):1-6.

[9] Wang Haijiao, Huang Ruina, Wang Xiaojun, Zheng Bili, Chen Peina, Zeng Xiujuan. Analysis on the hotspot of the platelet-rich plasma based on VOSviewer. Chinese Journal of Tissue Engineering Research, 2019,23(18):2947-2952.

[10] Zhihua Wei, Yaqing Lin, Yuhui Wu, Changqing Li. Family Business Research: A Bibliometric Analysis. China Economic Quarterly, 2014,13(1):27-56.

[11] Zhou Chaofeng. Comparative Study of Commonly Used Software for Bibiometrics. Central China Normal University, 2017.

[12] Zong Qianjin, Yuan Qinjian, Shen Hongzhou, Shu Xiaoyun. Mapping Knowledge Domains of Research Focus of China's Information Science in 2010 - One of Series Papers of Knowledge Mapping Research Group in Nanjing University. Journal of Intelligence, 2011,30(12):48-53.

[13] Hu Xiaomei, Wu Liyan, Wang Pingshui. Bibliometrics Analysis of Privacy Protection Research in Big Data Era Based on VOSviewer. Journal of Bengbu University, 2020,9(1):32-37.

[14] Xu Hanbing, Wang Jian, Li Xinzheng, Zhang Xiaoli. Visual analysis of employment psychology of contemporary college students based on VOSviewer. Health Vocational Education, 2019,37 (22): 41-45.

[15] Nees Jan van Eck and Ludo Waltman, Manual for VOSviewer version 1.6.8. 2018.

[16] Xu Hanbing, Wang Jian, Li Xinzheng, Zhang Xiaoli. Visual analysis of employment psychology of contemporary college students based on VOSviewer. Health Vocational Education, 2019,37(22):41-45.

[17] Li Tao. Research on reading promotion in university library based on bibliometrics. Journal of Academic Library and Information Science, 2018,36(06):108-114.

[18] Li Zhiqiang, Wang Yilun. The influence of mobile phone culture on ideological and political education in colleges and universities and countermeasure analysis. Leading Journal of Ideological \& Theoretical Education, 2014 (12): 95-98.

[19] Tang Yu. A survey report on the mobile phone dependence of college students in Lanzhou. News World, 2009,21 (1): 102-104.

[20] Xu Tingting, Cao Yongfu. Investigation of cell phone addiction in medical college students. Medicine \& Philosophy, (A),2016,37(6):90-93.

[21] Yie Xingdong. A review of researches on the internet addiction. Journal of Psychological Science, 2004,41(6):1446-1448.

\section{Authors' Profiles}

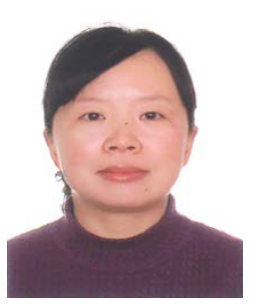

Han Xiyang is a doctor at the Affiliated Hospital of Hunan University of Science and Technology. Her research interests are Pediatrics and the mental health of college students.

How to cite this paper: Han Xiyang. " A visual analysis of the research on the use of mobile phones by college students based on VOSviewer ", International Journal of Education and Management Engineering (IJEME), Vol.10, No.6, pp.10-16, 2020. DOI: 10.5815/ijeme.2020.06.02 